\title{
ValênCia do Nome Deverbal e Nominalidade PROTOTÍPICA"
}

\author{
(Valency of Deverbal Nouns and Prototypical Nominality) \\ Roberto Gomes Camacho \\ (Universidade Estadual Paulista - São José do Rio Preto)
}

ABSTRACT. This paper aims to show that deverbal nouns preserve the argument structure of the corresponding input verb and that the overt or non-overt expression of their arguments within the term depends on a set of semantic and pragmatic factors, mainly related to the shared short-term information by the speech act participants. As a theoretical implication, this analysis preserves the idea that there is a gradual process of verbal decategorization, which is reflected in the different kinds of grammatical relation markings. As the verbal predicate gradually gains nominal status, the clausal markings (agreement, word order and the like) give way to prepositional marking or some other device, like adjectival modification or the use of possessive pronouns which are perfectly appropriate to follow a nominal head.

KEY-WORDS: nominalization; deverbal noun; verbal decategorization; parts of speech.

RESUMO: O objetivo deste trabalho é mostrar que os nomes deverbais preservam a estrutura argumental do verbo input correspondente e que a especificação ou não dos argumentos no interior do termo nominal depende de um conjunto de fatores pragmáticos, especialmente relacionados a informação de curto termo compartilhada pelos participantes da interação. Como implicação teórica, a análise preserva a idéia de que há um processo gradual de descategorização verbal, que se reflete nos diferentes tipos de marcação gramatical. Conforme o predicado verbal ganba estatuto nominal, as marcações tipicamente oracionais dão lugar a outros mecanismos, como marcação argumental por preposição, modificação por adjetivo, uso de pronomes possessivos, que acompanham apropriadamente um núcleo nominal.

PALAVRAS-CHAVE: nominalização; nome deverbal; descategorização verbal; classes de palavra.

* Este trabalho faz parte do projeto de pesquisa $A$ estrutura argumental dos nomes deverbais, realizado de 2002 a 2005 para o CNPq, na qualidade de Bolsa de Produtividade de Pesquisa.

D.E.L.T.A., 23:2, 2007 (321-337) 


\section{Introdução}

Segundo Dik (1997), uma nominalização é uma construção encaixada que tem propriedades em comum com um termo nominal primário, como é o caso de demissão em (1).

(1) Maria lamentou a demissão de Pedro.

Com efeito, em (1), o constituinte na função de paciente do nome deverbal aparece sob a forma de possuidor, que é especialmente adequada para expressar relações no interior de sintagmas nominais. O fato de Pedro aparecer em (1) sob a forma de sintagma de possuidor é interpretado por Dik como uma propriedade nominal, e o SN a demissão de Pedro é descrito como uma construção encaixada na posição de complemento da oração matriz que tem como núcleo o predicado lamentou (cf. Dik 1997:157-8).

A principal implicação teórica dessa posição é a de que nomes deverbais dispõem de valência potencial como outras construções encaixadas. Como um tipo derivado de nome, os deverbais podem ser mono, bi e trivalentes, na mesma medida em que são os verbos que lhe dão origem, conforme entende Dik (1985; 1997). Entretanto, essa interpretação de valência por herança natural não é destituída de controvérsia justamente porque a organização sintática de um nome deverbal raramente expressa todos os constituintes de sua estrutura argumental, como se observa em (2a).

(2)a se eu fizer este gato e e deixasse durante doze mil anos... ele vai continuar sendo um gato sem valor... (...) não tem:: nenhuma... um valor artístico esta representação (EF-SP-405)

O nome grifado em (2a), cujo esquema de predicação (cf. Dik 1989) pode ser representado em (2b), constitui um predicado cujos argumentos potenciais são desprovidos de expressão formal.

(2)b $\left(e_{i}\left[f_{i}:\right.\right.$ representação ${ }_{N}\left(f_{i}\right)\left(x_{i}:\right.$ eu $\left.\left.\left(x_{i}\right)_{A g}\left(x_{i}: \text { gato }\left(x_{j}\right)\right)_{G o}\right]\left(e_{i}\right)\right)$

Essa característica do nome deverbal subsidia a hipótese postulada por Mackenzie (1985; 1996) de que a predicação nominalizada prototípica é, na realidade, avalente, posição sustentada também por Basílio (1989), que alega ser a estrutura argumental obrigatória nos verbos e opcional nos 
nomes. Neste trabalho, defendo a hipótese alternativa de que nomes deverbais preservam a estrutura argumental do predicado verbal correspondente, conforme sugestão de Dik (1985), também aplicada por Neves (1996) e Camacho \& Santana (2004). Há razões funcionais para considerar que, na ocorrência contida em (2a), os argumentos, expressos por anáfora zero na estrutura interna do sintagma encabeçado por representação, retomam a referência dos termos eu e gato, para o primeiro e o segundo argumento, respectivamente, um fenômeno pragmático de identificação de referentes amplamente conhecido por caracterizar também a estrutura valencial de predicados verbais.

Essa linha de argumentação tem a seu favor um outro aspecto, teoricamente relevante, relacionado à valência potencial dos nomes deverbais, que é a própria caracterização categorial das classes de palavras. A conhecida incomensurabilidade tipológica das diferentes línguas, com base na relação entre a percepção de categorias ontológicas e as categorias gramaticais disponíveis, não tem deixado imune nem mesmo a suposta distinção universal entre nome e verbo. Hengeveld (1992) mostra que os sistemas de classes de palavras podem ser ordenados hierarquicamente, conforme as línguas disponham ou não das quatro classes de palavras que exercem função tipicamente predicadora, como na hierarquia contida em (1).

(3) Verbo $>$ Nome $>$ Adjetivo $>$ Advérbio

Essa hierarquia pressupõe que uma categoria de predicados é mais provável de ocorrer como uma classe de palavra separada se estiver localizada mais à esquerda do continuum; pressupõe, além disso, que cada estágio do continuum pode servir de ponto de corte para as diferentes tipos de línguas. O português, assim como a maioria das línguas ocidentais conhecidas, dispõe de uma classe separada de palavra para cada ponto do continuum em (3). Há, todavia, línguas, como o mandarim, que dispõem apenas de nomes e verbos e outras, como o tuscarora, língua ameríndia da América do Norte, que dispõem somente de verbos.

É por isso que os pesquisadores que reconhecem alguma universalidade na distinção entre nomes e verbos sentem a necessidade de apoiar-se numa categorização de base prototípica, não numa categorização de base referencial. O ponto mais interessante sob esse aspecto é o de que os nomes deverbais não são nem nomes, nem verbos prototípicos e uma boa hipótese 
a defender é que quanto mais ele preserva a estrutura argumental mais próximo ele está da referência a um estado de coisas e, portanto, mais distante da nominalidade prototípica.

De acordo com a definição de classes de palavras, proposta por Hengeveld (1992), o português deve ser tipologicamente classificado como uma língua rígida, diferenciada, já que dispõe das quatro categorias separadas de predicados, ou seja, o verbal, o nominal, o adjetival e o adverbial, desempenhando quatro diferentes funções. Em contraste, línguas flexíveis, como o tuscarora, dispõem de uma única forma para cobrir diferentes funções no sistema de classes de palavras. Línguas especializadas, como o português, precisam contar com operações transcategoriais para derivar nomes de verbos, o que costuma ocorrer, por exemplo, com processos produtivos de sufixação ${ }^{1}$.

$\mathrm{Na}$ visão mais tradicional, a nominalização envolve tanto a aquisição de propriedades nominais como a perda de propriedades verbais, numa relação de oposição discreta. Entretanto, segundo Malchukov (2004) a pesquisa tipológica mais recente tem reconhecido que a articulação entre os dois processos acarreta possibilidades mais graduais que discretas e, portanto, empiricamente mais adequadas. E, com efeito, as operações transcategoriais, quando aplicadas à nominalização, envolvem tanto descatecorização quanto recategorização.

O termo 'descategorização', introduzido inicialmente por Hopper \& Thompson (1984), indica que verbos e nomes tendem a perder algumas das propriedades morfossintáticas associadas respectivamente com suas funções primárias de relatar eventos e referir-se a termos. Assim, um verbo usado como expressão referencial também adquire algumas das propriedades nominais, como caso, determinação, modificação etc, e é por isso que o termo 'nominalização' reúne propriedades relacionadas tanto ao processo de deverbalização quanto ao de substantivização (cf. Malchukov 2004) ${ }^{2}$.

1 Segundo Basílio (1989), os nomes abstratos, formados a partir de verbos, servem para atender a exigências sintático-semânticas do discurso, o que justifica a enorme produtividade dos processos de substantivização a partir de verbos.

2 Para Malchukov (2004), os termos 'nominalização' e 'nome deverbal' compreendem duas diferentes categorias no processo de deverbalização gradual. Neste trabalho, usa-se 'nominalização' para designar o processo de transposição categorial em geral, o que inclui nomes deadjetivais, reservando-se o termo 'nome deverbal' para o tipo de nominalização cujo input é um predicado verbal. 
Em seu funcionamento, os processos de recategorização (R) e descategorização (D) preservam uma independência relativa: como demonstram Hopper \& Thompson (1984), do mesmo modo que descategorização não acarreta necessariamente recategorização, também recategorização não acarreta necessariamente descategorização. Malchukov menciona quatro possíveis combinações no tratamento de construções completivas encaixadas:

(i) $[-\mathrm{D} /+\mathrm{R}]$ complementos sentenciais: I know that he comes.

(ii) $[+\mathrm{D} /-\mathrm{R}]$ infinitivos: I want him to come early.

(iii) $[-\mathrm{D} /+\mathrm{R}]$ nominalização oracional: I disapprove of his driving the car so caressly.

(iv) $[+\mathrm{D} /+\mathrm{R}]$ nomes deverbais : $\quad I$ did'nt see John's arrival.

(Malchukov 2004:7)

A construção em (i) se refere a um complemento sentencial: embora ocorra numa posição de objeto (SN), ela retém a estrutura de uma sentença e raramente adquire traços nominais. No caso em (ii), os infinitivos retêm a sintaxe interna de um SV em relação a alguns traços semânticos, como possibilidade de argumento, aspecto e voz, mas não podem assumir outras propriedades tipicamente verbais, como tempo e modo e, no caso citado do inglês, concordância e combinação com um sujeito nominativo da forma sentencial. O caso em (iii) combina, por seu lado, traços nominais e verbais: é capaz de receber objeto, enquanto o sujeito é expresso como um SN na forma de possuidor. Finalmente em (iv), o verbo é completamente assimilado a um nome: assume todas as flexões nominais e raramente preserva traços de verbo. Enquanto complementos sentenciais e nomes deverbais representando os pólos opostos na escala são as classes mais ou menos universais, como as de verbo e nome respectivamente, as línguas diferem muito mais quanto ao estatuto categorial das classes intermediárias.

Em face dessa aproximação potencialmente relevante entre classes de palavras e processos de (des/re-categorização, o objetivo deste trabalho é mostrar que o nome deverbal tem uma funcionalidade ambígua entre referir e predicar e que essa ambigüidade depende crucialmente de assumir a existência de valência potencial. Assim, quanto maior o grau de ajuste de um nome deverbal à expressão formal de um termo de primeira ordem, tanto mais próximo é seu significado de "entidade" e, portanto, mais próximo da 'nominalidade' prototípica, e, vice-versa, quanto mais ele preserva 
a estrutura argumental do verbo original, tanto mais próximo está da 'verbalidade' prototípica.

Embora o trabalho todo contenha uma análise empírica quantitativamente exaustiva ${ }^{3}$, este artigo se restringe à análise qualitativa de alguns casos especialmente selecionados. A amostra em que essa análise se baseia é constituída por 181 ocorrências extraídas de um corpus maior coletado por Santana (2005), que inclui 305 casos de nomes deverbais e deadjetivais, a partir de três inquéritos do Projeto NURC-SP, o inquérito EF-377, representando as Elocuções Formais (cf. Castilho \& Preti 1986), o inquérito DID-237, correspondente aos Diálogos entre Informante e Documentador (cf. Preti \& Urbano 1988) e, finalmente, o inquérito D2-360, representando os Diálogos entre Dois Informantes (cf. Castilho \& Preti 1987).

Este trabalho se organiza do seguinte modo: a seção 1 apresenta motivações semânticas e pragmáticas para a ausência de manifestação formal da valência potencial dos nomes deverbais, com base no princípio de economia, que representa uma pressão para a simplificação máxima da expressão. A seção 2 apresenta algumas generalizações que conduzem às evidências de correlação entre valência e categorização prototípica dos nomes deverbais. A seção 3, que trata das considerações finais, faz um balanço ligeiro da discussão.

\section{Motivações semânticas e pragmáticas para a não expressão de valência}

Se a valência potencial pode ser expressa no exterior do núcleo nominal, é possível considerar como argumentos reais alguns tipos de termos não-manifestos expressos por anáfora zero.

O primeiro tipo de zero anafórico representa um participante semanticamente compartilhado com o predicado da oração matriz, como mostra (4a).

(4)a ajudar um pessoal que que que tem me pedido para fazer:: programação da da de sucos do Lanjal e eu acho que a televisão é completamente:: diferente do que a gente assiste eb lá no no teatro (DID-SP-234)

3 Uma versão completa dessa discussão será publicada em Camacho (2007). 
Note que a mesma nominalização com o argumento especificado em (4b) não seria uma construção aceitável por razões de redundância, já que o agente já se acha mencionado no objeto indireto de pedir, que funciona como núcleo da predicação matriz.

(4)b ajudar um pessoal que que que tem me pedido para fazer:: programação de sucos do Lanjal ( *por mim)

O segundo tipo de zero anafórico representa termos que recuperam alguma entidade dada, já mencionada no texto precedente, não necessariamente na predicação matriz, como se vê em (5a).

(5)a então numa vida desse tipo... a preocupação principal esta centrada na sobrevivência... (EF-SP-405)

Como o tópico do texto é a arte do paleolítico, há várias menções anteriores ao homem pré-histórico. É por isso que, em (5b), a mesma nominalização com o argumento especificado continuaria sendo uma construção aceitável.

(5)b então numa vida desse tipo... a preocupação principal do homem pré-bistórico está centrada na sobrevivência... (EF-SP-405)

Isso significa que, nesse aspecto, (5a) é diferente de (4a): a manifestação ou não do argumento em (5a) é uma escolha real do falante, diferentemente de (4a) que bloqueia a manifestação do argumento agentivo.

O terceiro tipo de expressão por zero não é anafórico, mas catafórico. Há um número reduzido de casos em que o argumento não-manifesto pode ser recuperado no contexto imediatamente seguinte mediante o uso de uma oração relativa atuando como modificador do núcleo nominal, como se vê em (6a).

(6)a é MUIto difícil a gente desenhar estritamente o que a gente vê a gente separar a percepção... da... do conceito que nós fazemos do objeto...(EF-SP-405:56)

Como (4a), a inserção de um termo na posição argumental torna a construção agramatical também por razões de redundância, como se vê em (6b).

(6)b separar a percepção do objeto (*por nós\} do conceito que nós fazemos do objeto 
Os dados analisados mostram que há, portanto, dois casos de zero: um com motivação semântica e o outro com motivação pragmática. Ambos são governados pelo mesmo princípio funcional de economia que representa uma pressão para a simplificação máxima da expressão. Trata-se aqui, de acordo com Haiman (1983), do princípio de economia sintagmática ou discursiva que explica a tendência pela omissão de informação redundante ou recuperável no contexto.

A economia representa uma tendência para o mínimo esforço e simplificação máxima da expressão. A economia sintagmática é a tendência para reduzir o comprimento ou a complexidade do enunciado, de modo que as expressões mais freqüentes no uso tendêm a reduzir-se fonologicamente e a informação redundante ou recuperável no contexto comunicativo tende a ser omitida.

Segundo Cristofaro (cf. 2003: 248-9), a economia sintagmática explica a correlação entre a predeterminação de traços semânticos de estados de coisas conectados e os fenômenos morfossintáticos que levam à não especificação de informação correspondente. Se, por exemplo, a referência temporal, a aspectual ou valores modais do estado de coisas dependente são predeterminados pelos traços semânticos do predicado principal, ou pela relação de conexão entre os dois estados de coisas, eles não precisam ser especificados no verbo codificando o estado de coisa dependente. Similarmente, se os dois estados de coisas compartilham participantes, também a referência a esses participantes pode ser omitida na forma dependente. Esse princípio explica casos de compartilhamento argumental como o de (7) abaixo.

(7) isto é de caça... que éo que oferece... uma resistência (*da caça) porque a:: fruta esta na então eles não precisavam se preocupar... (EF-SP-450)

Há, no entanto, casos de compartilhamento de participantes em que o argumento não-expresso não é semanticamente determinado pelo predicado da oração matriz. Quando os participantes são predeterminados, o falante pode excluir a referência a eles porque a informação correspondente está implicada na relação de subordinação, ou em outro tipo de combinação de orações. Todavia, quando os participantes não são semanticamente predeterminados, e não há referência aberta a eles, o modo como se recupera a informação depende do conhecimento de curto prazo pragmatica- 
mente compartilhada pelos interlocutores. Um bom exemplo desse tipo de não expressão argumental é (8b).

(8)a toda e qualquer manifestação que a gente for procurar vai ter que estar necessariamente ligada... a esta preocupação vital do homem pré-histórico de... se conservar vivo... (EF-SP-405:50)

b então a preocupaçãa central... vai ser em torno da caça... (EF-SP-405:51)

Está claro em (8b) que a expressão do primeiro argumento é o homem pré-histórico, enunciado alguns momentos antes no mesmo contexto discursivo, como aparece em (8a). O mesmo argumento na segunda menção, representada por (8b), é morfossintaticamente licenciado, mas não é expresso por ser informação pragmaticamente compartilhada pelos participantes da interação. Nesse caso, a construção de (8b), desprovida de manifestação valencial, não envolve perda real de informação, porque o ouvinte sabe que, se a construção de (8b) é assim usada pelo falante, é porque ela compartilha o participante sujeito potencial não com o predicado matriz, mas com o contido em (8a), mencionado um momento antes na situação discursiva. Segundo Cristofaro (2003: 250-1), embora esse tipo de construção seja apenas outro exemplo do mesmo Princípio de Economia, ele reflete o fato de que essa situação de compartilhamento é mais comum no nível do discurso, e a organização estrutural é motivada pelas condições do uso.

Nos predicados não-referenciais, como em (9), e nos predicados contendo argumentos com referência indeterminada, como (10), as condições semânticas, no caso do primeiro, e as pragmáticas, no caso do segundo, são instruções que levam o ouvinte a não esperar acessibilidade a nenhum referente específico, fenômeno que não é restrito aos nomes deverbais.

(9) ela quer saber as matérias que ela vai ter.. o curso:....o segundo ciclo que ela pretende fazer... sabe? bom já está numa:: idade de definição quanto ao segundo ciclo porque elas já estão na oitava série as mais velhas não é? (D2-SP-360:168)

(10) aumenta um pouco mais a procura de engenbeiro civil... depois cai... (D2-SP-360)

\section{Algumas generalizações e implicações teóricas}

Em termos tipológicos, pode-se predizer que certas percepções 'prototípicas' de entidades próximas a coisas são codificadas numa forma gra- 
maticalmente identificável como nomes, ao passo que percepções prototípicas de ações ou eventos são gramaticalmente codificadas como verbos (cf. Hopper \& Thompson 1984).

As classes dos nomes e a dos verbos têm correlatos semânticos que correspondem aproximadamente a entidades percebidas no mundo real. Para os nomes, a entidade é qualquer coisa similar a 'objeto', ou a uma percepção do que Givón (1979) designa 'estabilidade temporal (time-stability). Ao contrário, os verbos são prototipicamente 'ações' ou 'eventos': representam percepções sem estabilidade temporal. A dualidade perceptual reflete-se numa tendência universal de associar entidades temporalmente estáveis com a classe gramatical dos nomes e entidades não temporalmente estáveis com a classe gramatical dos verbos.

Como essa correlação tem validade universal, Hopper \& Thompson aplicam à noção de categoria o princípio cognitivo da prototipicidade, desenvolvido por Rosch (1973 apud Hopper \& Thompson 1984). Segundo esse princípio, como a categorização humana não é arbitrária, mas procede de exemplares mais centrais para exemplares mais periféricos, são prototípicos os exemplares mais centrais da categoria, justamente os que parecem mais salientes aos falantes.

Assim, o critério semântico de estabilidade temporal, invocado por Givón (1979) para determinar a prototipicidade dos nomes, não é suficiente para atribuir uma classe lexical a uma dada forma. Segundo Hopper \& Thompson, a Prototipicidade de categorias lingüísticas depende não apenas de propriedades semânticas verificáveis, mas também, e talvez até mais crucialmente, da função lingüística no discurso (cf. Hopper \& Thompson 1984:708). Nem sempre o uso de um nome é capaz de construir ou de identificar um referente (cf. Dik 1989:114), como ocorre, por exemplo, com o termo definiçãa na sentença (11).

(11) ela quer saber as matérias que ela vai ter.. o curso:....o segundo ciclo que ela pretende fazer... sabe? bom já está numa:: idade de definição quanto ao segundo ciclo porque elas já estão na oitava série as mais velhas não é? (D2-SP-360:168)

Segundo Hopper \& Thompson, o fato semântico de que um termo denote uma entidade concreta, visível etc (que já não é o caso de uma entidade de segunda ordem, como definição) não é crucial para determinar que esse termo é um nome prototípico. Em vez disso, o fato mais impor- 
tante e decisivo é o de que o nome deve exercer algum papel no discurso em que ele figura, seja construindo seja identificando um referente na situação de comunicação, como empregar o nome definição agora em (12), um caso típico de referência identificadora, em que o nome manifesta o conjunto completo de possíveis constituintes convencionais.

(12) Você entendeu aquela segunda definição de sintagma que o professor deu na aula de ontem?

Do mesmo modo, os traços semânticos do verbo prototípico (visibilidade, movimento e efetividade) não são suficientes para determinar sua prototipicidade. Para qualificar-se como verbo prototípico uma forma deve referir-se à ocorrência de um evento do discurso. Assim, uma forma infinitiva, como acertar em (13), não constitui uma instância de verbo prototípico, o que se dá com (14), em que a forma finita representa o evento de acertar. Também para verbos, é o papel discursivo da forma empregada que consiste, para Hopper e Thompson, no principal fator que determina se ele é um membro central ou periférico de sua categoria.

(13) Acertar traves exige habilidade.

(14) Ronaldo acertou a bola na trave para provar que é habilidoso.

São essas relações pragmáticas e semânticas que determinam o grau de complexidade categorial e, portanto, o de versatilidade sintática dos nomes deverbais, não necessariamente a redução de argumentos.

O nome deverbal tem como modelo prototípico o nome comum nãoderivado e, como tal, usa a expressão de possuidor, típica dos nomes comuns, para a expressão argumental. O modelo prototípico de expressão de um tipo primário de termo, que se refere a uma entidade de primeira ordem, contém constituintes como determinantes, quantificadores, possuidores, modificadores e, por definição, um nome como núcleo. Portanto, nomes deverbais devem ajustar-se ao modelo de expressão de um termo de primeira ordem, como se vê na figura 1. 


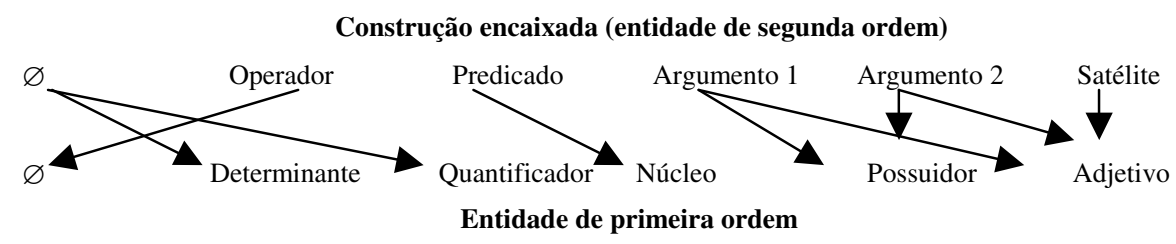

Figura 1: Ajustes formais (Dik 1997:158)

Entretanto, enquanto o nome deverbal fizer referência não a uma entidade de primeira ordem, mas a uma entidade de ordem superior ${ }^{4}$, a correspondência entre os argumentos do nome e os do verbo input, deve estar representada na estrutura subjacente de ambas as classes de palavras.

Um bom argumento para sustentar uma diferença entre nomes de primeira e nomes de segunda ordem são os casos de dupla manifestação de forma de possuidor, principalmente na estrutura do tipo genitivo-possessivo que caracteriza o inglês. Embora o nome deverbal se ajuste ao modelo dos nomes prototípicos, há uma diferença absoluta entre eles, já que a dupla manifestação de possuidor só é licenciada para os nomes deverbais. Compare (15a) com (15b).

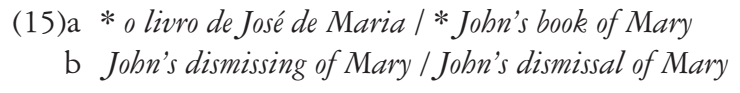

A única situação em que nomes deverbais poderiam assimilar-se completamente a nomes de primeira ordem é aquela em que eles não se referem a estados de coisas (nominais de ação), mas ao resultado de estados de coisas de ação, como em (16a) em oposição a (16b).

(16)a Aquela construção do alto da colina é muito sólida.

b A construção da casa demorou dois anos.

\footnotetext{
4 Lyons (1977) propõe uma tipologia de entidades, que foi aproveitada por Dik 1989), segundo a qual, entidades de primeira ordem (termos, para Dik) são objetos físicos que, como podem ser localizados no tempo e no espaço, são avaliados em termos de sua existência. Entidades de segunda ordem, por sua vez, constituem eventos, processos, estados de coisas localizados no tempo e que podem ser avaliados em termos de sua realidade. Por fim, entidades de terceira ordem são proposições que, como tal, podem ser avaliadas em termos de suas condições de verdade. Assim, para Dik (1989) entidades de ordem superior são as de segunda e de terceira ordem.
} 
O nome destacado em (16a) deriva-se do verbo construir, mas não é provido de estrutura argumental, porque não se refere ao estado de coisas, mas ao resultado dele e, nesse caso, o sintagma do alto da colina consiste em localizar a entidade referida para o ouvinte. Já o mesmo nome deverbal em (16b) representa uma predicação encaixada na posição de sujeito. É possível aplicar os rótulos categoriais de (17) para as duas expressões possíveis do nome em comparação ao verbo:

$$
\begin{aligned}
& \text { (17) } \text { construir }>\text { construção }^{1}>\text { construção }^{2} \\
& {[+\mathrm{V}-\mathrm{N}] \quad[+\mathrm{V}+\mathrm{N}] \quad[-\mathrm{V}+\mathrm{N}]}
\end{aligned}
$$

No cline da deverbalização proposto por Malchukov (2004), a nominalização só perde a condição de referência a um estado de coisas quando se transforma realmente num nome de primeira ordem. As categorias mais externas e respectivas camadas são mais prontamente afetadas pelas operações transcategoriais do que as mais internas. Desse modo, a valência é, na visão do autor, a camada semanticamente mais próxima do lexema verbal e, portanto, mais preservada do que as demais categorias. Considerando os processos complementares de deverbalização e de nominalização, Malchukov propõe o modelo contido em (18):

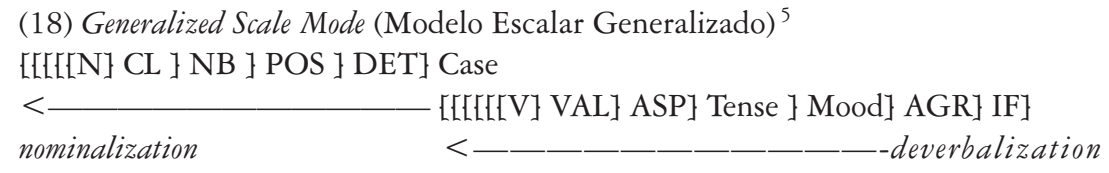

O que ocorre com o termo referido por $\underline{\text { construção }}^{2}$ no esquema em (18) é que além de descategorizar-se a partir de um lexema verbal, ele continua a seguir o processo, recategorizando-se como termo referente a uma entidade de primeira ordem; nesse caso específico, perde valência e recebe, todas as marcas possíveis de um nome prototípico. Já o termo referido por construção $^{1}$ sofre apenas processo de descategorização, o que implica preservação da referência a uma entidade de ordem superior e, conseqüentemente, da estrutura argumental do predicado verbal correspondente.

5 As abreviaturas têm o seguinte significado: no pólo nominal, $\mathrm{N}$ representa nome; $\mathrm{CL}$, classificador; NB, número; POS, possuidor; DET, determinante. Já no pólo verbal, V representa verbo; VAL, valência; ASP, aspecto; AGR, concordância; IF, força Ilocucionária. 
Malchukov não se refere a redução de valência nesse processo de descategorização, mas a efeitos de bloqueio (blocking effects); por exemplo, numa ocorrência como a forma gerúndivo-genitiva do inglês, contida em (19), o bloqueio atinge o argumento agente, permanecendo o argumento paciente com a mesma marca de acusativo que mantém em sua relação com o predicado verbal, isto é, como se não fosse afetado pelos efeitos de bloqueio.

(19) I disapprove of his driving the car so caressly

$\mathrm{Na}$ realidade, o bloqueio não reduz o número de relações gramaticais próprias da categoria verbal, mas o preserva, introduzindo apenas outro tipo de manifestação formal. O uso de preposições, como de e por constitui um dos mecanismos formais usados nos nomes deverbais para visibilizar as mesmas relações gramaticais de sujeito e de objeto do verbo, que em português, pelo menos, são geralmente marcadas por ordem de palavras, posição pré e pós-verbal respectivamente, e por concordância número-pessoal.

Essa interpretação encontra respaldo na proposta de classificação que Keizer (2004) faz das preposições do inglês no arcabouço teórico da Teoria da Gramática Funcional (Dik 1989; 1997). Defende a idéia de que elas podem atuar como elementos gramaticais (operadores) e como elementos lexicais (predicados). Na condição de categoria lexical, as preposições atuam como predicados de um lugar (transitivas), como em The book is on the table, e como avalentes (intransitivas), como em John is in. Já o uso gramatical está confinado às preposições of e by quando usadas para introduzir termos com as funções semânticas que podem ser atribuídas ao primeiro e segundo argumentos de predicados verbais ou adjetivais.

No espírito da proposta de Keizer (2004), em (16a), a preposição de em Aquela construção do alto da colina estabelece uma relação de modificador com o núcleo nominal, devendo, portanto, ser analisada como preposição lexical, e a relação especifica a localização de uma construção; já em (16b), A construção da casa, de estabelece uma relação argumental, consistindo, portanto, numa preposição gramatical. A mesma distribuição se sustenta nas relações estabelecidas pelas preposições por e em, nos exemplos de (20ab) e (21a-b), em que se percebe a correspondência entre preposição gramatical para relações argumentais e preposição lexical para relações de modificação. 


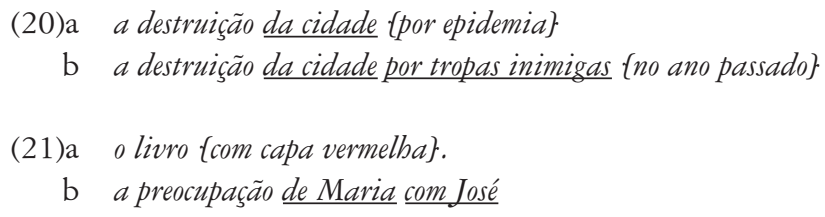

A relação de modificação, representada por colchetes nos exemplos de (20) e de (21), incidindo sobre um predicado nominal como em (20), indicam circunstância de causa (20a), de tempo (20b), especificação de referência (21a). Esses termos não requeridos pelo predicado são satélites, enquanto os termos grifados, que são requeridos pelo predicado, devem ser considerados verdadeiros argumentos.

\section{Considerações finais}

A hipótese que assumi consistiu inicialmente em mostrar que a ausência de manifestação fonológica da estrutura argumental da nominalização nos nomes deverbais não deve ser absolutamente considerada ausência de valência potencial. $\mathrm{Na}$ realidade, na maioria dos casos investigados, a expressão por anáfora zero é motivada semântica e pragmaticamente e, nos dois casos, pode ser atribuído a um princípio amplamente reconhecido na literatura funcional como Princípio de Economia.

A constatação de que os nomes deverbais contêm de fato uma estrutura argumental correspondente à do verbo de origem permitiu levar-me à comprovação da hipótese de que a nominalidade prototípica em línguas especializadas, como o português, é diretamente proporcional à potencialidade do nome de referir e predicar, potencialidade essa, diretamente vinculada à existência ou não de valência potencial. Nomes deverbais com potencial de referir-se a entidades de primeira ordem são destituídos de valência, enquanto nomes deverbais com potencial de referir-se a uma entidade de segunda ordem ou estado de coisas são necessariamente constituídos de estrutura valencial, não importando se os argumentos recebam ou não manifestação fonológica.

Recebido em outubro de 2006

Aprovado em março de 2007

E-mail: camacho@ibilce.unesp.br 


\section{REFERÊNCIAS BIBLIOGRÁFICAS}

Basílio, Margarida. 1989. Teoria Lexical. São Paulo: Editora Ática.

CAMACHO, Roberto Gomes. 2007. The argument structure of deverbal nouns in Brazilian Portuguese. Working Papers in Functional Grammar. 81 Amsterdam (no prelo).

\& Santana, Liliane. 2004. Argument structure of deverbal nouns in Brazilian Portuguese. Journal of Language and Linguistics 3, 2: 229-42.

Castilho, Ataliba. T.\& Preti, Dino. (orgs.) 1986. A linguagem falada culta na cidade de São Paulo: materiais para seu estudo. São Paulo: T. A. Queiroz, v. 1.

Castilho, Ataliba. T.\& Preti, Dino. (orgs.) (1987) A linguagem falada culta na cidade de São Paulo: materiais para seu estudo. São Paulo: T. A. Queiroz, v. 2.

Cristofaro, Sonia. 2003. Subordination. Oxford: Oxford University Press.

Dik, Simon C. 1985. Formal and semantic adjustment of derived constructions. In: Bolkstein et al. (eds). Predicates and terms in Functional Grammar. Dordrecht/Cinnaminson: Foris, p. 1-28. . 1989. The theory of functional grammar. Dordrecht: Foris. .1997. The theory of Functional Grammar. (Part II: Complex and Derived Constructions). Edited by Kees Hengeveld. Berlin/New York: Mouton de Gruyter.

Givón, Talmy. 1979. On understanding grammar. New York: Academic Press HaIMAN, John. 1983. Iconic and economic motivation. Language 59: 781-819. . 1992. Non-verbal predication. Theory, typology, diachrony. Berlin: Mouton de Gruyter, 1992.

Hopper, Paul. J. \& Thompson, Sandra A. 1980. The discourse basis for lexical categories in universal grammar. Language 60: 703-752.

Keizer, Evelien. 2004. English Prepositions in FGD. Paper presented at $11^{\text {th }}$ International Conference on Functional Grammar. Gijón, Espanha.

Lyons, John. 1977. Semantics. Cambridge: Cambridge University Press.

Mackenzie, J. Lachlan. 1985. Nominalization and valency reduction. In: Bolkestein, A. M. et al. (eds). Predicates and terms in Functional Grammar. Dordrecht/Cinnaminson: Foris, p. 31-51. 1996. English nominalizations in the layered model of the sentence. In: Devriend, B., Goossens, L., Auwera, J. van der (eds). Complex Structures: A Functionalist Perspective. Berlim/New York: Mouton de Gruyter, p.325-55. 
Malchukov, Andrej, L. 2004. Nominalization/verbalization: constraining a typology of transcategorial operations. Lincom: Lincom Europa.

Neves, Maria Helena M. Estudo da estrutura argumental dos nomes. In: Kato, M. (org.) Gramática do Português Falado. V. 5: Convergências. Campinas: Editora da UNICAMP/São Paulo: FAPESP, 1996, p.119154.

Preti, Dino \& Urbano, Hudinilson (orgs.). 1988. A linguagem falada culta na cidade de São Paulo: V.3: materiais para seu estudo. São Paulo: T. A. Queiroz/FAPESP.

SANTANA, Liliane. 2005. A expressão da estrutura argumental dos nomes derivados. Dissertação de Mestrado. São José do Rio Preto: Universidade Estadual Paulista. 